\title{
“A CIDADE É UMA SÓ” \\ E AS DESIGUALDADES SÃO INÚMERAS
}

\author{
"THE CITY IS ONLY ONE" \\ AND THE INEQUALITIES ARE COUNTLESS
}

\section{"LA VILLE EST SEULEMENT UNE" \\ ET LES INÉGALITÉS SONT NOMBREUSES}

Fábio Ávila Arcanjo.

RESUMO:

A desigualdade social é um tema recorrente na filmografia brasileira. Podemos estabelecer como ponto de partida os filmes desenvolvidos pela "Caravana Farkas", com destaque para os realizados na década de 1960. O ponto nevrálgico desses filmes era evidenciar as desigualdades existentes no país, fazendo um contraponto com a produção propagandista, em voga, que buscava criar imagens ufanistas do país. A partir daí, inúmeras producões voltadas para temáticas sociais foram e continuam sendo concebidas. Diante disso, é pertinente nos perguntarmos: qual a importância do trabalho de um cineasta como Adirley Queirós? É possivel responder essa questão analisando o tema abordado em seus filmes e a mise-en-scène utilizada para transformá-los em discurso filmico, em que há um trabalho de rememoração do processo de exclusão social decorrente da construção e inauguração da cidade de Brasilia. Em suma: há um abismo entre o plano piloto e as cidades satélites e o cineasta volta o seu olhar para essa relação desigual. Isto posto, adotamos como corpus para o
ABSTRACT:

Social inequality is a recurring theme in Brazilian filmography. We can establish as a starting point the films developed by Caravana Farkas, especially those made in the 1960s. The main point of these films was to highlight the inequalities existing in the country, making a counterpoint to the propagandist production, in vogue, that sought to create nationalist images of the country. From then on, numerous productions focused on social themes have been being conceived.Given this scenario, it is pertinent to ask ourselves how important the work of a filmmaker like Adirley Queirós is. The answer demands analyzing the theme addressed in his films and the mise-enscène used to transform them into filmic discourse, in which there is a work of remembrance of the process of social exclusion resulting from the construction and inauguration of the city of

Brasilia. To sum up, there is a gap between the pilot plan and the satellite cities. The filmmaker turns his gaze to this unequal relationship. That said, we adopted as a corpus for this
RESUMÉ:

L'inégalité sociale est un thème récurrent dans la filmographie brésilienne. Nous pouvons établir comme point de départ les films développés par la "Caravana Farkas", en particulier ceux réalisés dans les années 1960. Le point névralgique de ces films était de mettre en avant les inégalités existantes dans le pays, s'opposant avec la production propagandiste, en vogue, qui cherchait à créer des images patriotiques du pays. Depuis ces événements, d'innombrables productions autour des thématiques sociales voient le jour. Ainsi, il est pertinent de se demander quelle est l'importance du travail d'un cinéaste comme Adirley Queirós? I/ est possible de répondre à cette question en analysant le thème abordé dans ses films ainsi que la mise-enscène utilisée pour les transformer en discours filmique, oú il y a un travail de remémoration du processus d'exclusion sociale provenant de la construction et de l'inauguration de la ville de Brasilia. En somme: Il y a un abime entre le plan pilote et les villes satellites, et le cinéaste parcours du regard cette relation 
presente artigo o documentário "A cidade é uma só?", produzido o em 2011 e nossa análise se pautará no processo de discursivização da memória.

\section{PALAVRAS-CHAVE:}

Documentário; Desigualdade Social; Ceilândia; Memória. article the documentary $A$ cidade é uma só? (2011) and our analysis will be based on the process of turning memory into discourse.

\section{KEYWORDS:}

Documentary; Social Inequality; Ceilândia; Memory. inégale. Ceci étant,le documentaire" A cidade é uma só? ", produit en 2011, est adopté comme corpus pour le présent article, et notre analyse s'axera sur le processus de narration de la mémoire.

MOTS-CLÉS:

Documentaire,

Sociale; Ceilândia; Mémoire.

L'inégalité

\section{INTRODUÇÃO}

Em entrevista concedida para a revista "Negativo", o cineasta Adirley Queirós afirma que o cinema "é um meio de problematizar relações, estabelecer diálogos e contar histórias" (QUEIRÓS, 2013, p. 18). Com base nessa asserção, duas questões pertinentes se imbricam: a primeira gira em torno da maneira pela qual esses três predicados encontram ressonância em sua pequena, porém singular cinematografia. Lembrando que o presente artigo primará em analisar aquela que pode ser considerada a obra divisora de águas na carreira desse cineasta - "A cidade é uma só?" -, produzida no ano de 2011 e lançada nos cinemas em 2013. A chave de resposta para essa primeira questão poderá ser ensaiada ao longo do texto, embora estejamos longe de querer esgotar todas as possibilidades concernentes a essa curiosa obra.

A segunda questão poderá ser respondida antes do desenvolvimento de nosso artigo, pois ela funciona como uma espécie de "âncora" para a obra fílmica. A partir do momento em que Adirley Queirós afirma que o cinema é um instrumento voltado para contar histórias, é válido nos perguntarmos que tipos de histórias são essas. Podemos nos valer das ideias construídas por Sírio Possenti (2015), quando o linguista, amparado pelo pensamento de Michel Foucault (1972), estabelece um contraponto entre a história tradicional - aquela que seria narrada pelos vencedores e que voltava o seu olhar apenas para o que era visível - e a chamada história serial, que possibilita o incremento de "estratos de acontecimentos dos quais uns são visíveis até mesmo pelos contemporâneos, e, debaixo destes, outros acontecimentos invisíveis, imperceptíveis e que são completamente diferentes" (POSSENTI, 2015, p. 51).

Em nosso objeto de estudo, a história tradicional - de caráter oficial - é aquela que constrói uma narrativa cujo ponto fulcral é a construção da cidade de Brasília. Tal acontecimento dá origem a um processo de "higienização" territorial, sendo a nova capital federal, bem como as cidades satélites, produtos da ação de dois grupos: GER (Grupo Executivo de Remoção) e a chamada CEl (Campanha de Erradicação de Invasões) que, não por acaso, pensando em termos morfológicos, é uma raiz. linguística da cidade referenciada no título do filme. O que estamos descrevendo é uma espécie de mise-en-abyme, pois há, por trás da história trás da história tradicional, uma segunda história, serial, que seria a dos esquecidos, daqueles que foram enganados e que foram relegados a uma invisibilidade, uma vez que sua presença "sujaria" a imagem cosmopolita que se estava tentando vincular para a cidade de Brasília. É para essa história que "A cidade é uma só?" volta o seu olhar.

\section{CARÁTER FRONTEIRIÇO}

Antes de partirmos para uma análise mais acurada, é interessante examinar o caráter híbrido do filme por meio de duas possibilidades: afinal, ele é uma narrativa ficcional que lança mão de estratagemas pertencentes ao gênero documentário ou ele é um cinema documental imbuído de ficcionalidade? A enunciação fílmica "embaralha" de forma tão acentuada esses dois gêneros, que a tarefa de elaborar uma definição estanque acaba sendo malfadada. Expliquemos isso melhor:

"A cidade é uma só?" narra a trajetória de três personagens: Dildu - um faxineiro que, nas horas vagas, gasta toda a sua energia em uma condenada campanha política para o cargo 
de deputado distrital pelo fictício PCN (Partido da Correria Nacional); Zé Bigode - um corretor imobiliário, que percorre a cidade de Ceilândia em busca de lotes que, em um futuro, poderão the proporcionar uma almejada lucratividade; e Nancy - uma cantora que vivenciou os impactos da CEl, sendo usada, juntamente com outras crianças, para participar de um jingle.

O objetivo dessa peça publicitária era, justamente, convencer

moradores

acerca das potenciais benesses que viriam caso eles acatassem, sem maiores protestos, a velada ordem de despejo. A pergunta que se faz, tendo em vista essa pequena sinopse, é a seguinte: Por que a produção em questão é caracterizada como híbrida?

Uma possível chave de leitura gira em torno do funcionamento daquilo que nomeamos de enunciação fílmica, que, como todo processo de enunciação, aciona as categorias dêiticas pessoa, espaço e tempo. O hibridismo genérico, isto é, o esfacelamento fronteiriço entre o cinema ficcional e o cinema documentário encontra lugar, na obra de Adirley Queirós, através do acionamento da categoria pessoa. Naquele, comumente, nos referimos aos atores como personagens de determinadas produções fílmicas, ao passo que, neste, seguindo a nomenclatura adotada por Bill Nichols (2014), os entrevistados costumam ser referenciados como atores sociais. Em "A cidade é uma só?" apenas Nancy pode ser considerada uma atriz social. Em contrapartida, Dildu e Zé Bigode são caracterizações ficcionais. E mesmo a história de Nancy possui traços de ficcionalidade, uma vez que, no início da projeção, somos informados que ela é prima de Dildu, o que é, sabidamente, falso.

- questionamento que se coloca é o seguinte: por se tratar de uma história documental que busca revelar as "verdades" escondidas nas trajetórias traçadas pelos sujeitos silenciados, não seria um contrassenso utilizar elementos ficcionais? Essa questão gira em torno da relação do cinema documental com dois aspectos: realidade e ficcionalidade. $\bigcirc$ primeiro aspecto é tratado de forma relevante pelo teórico brasileiro Fernão Pessoa Ramos.

Um documentário precisa mostrar a realidade? Mas de qual realidade estamos falando, dentro do leque de interpretações possiveis que o mundo oferece para mim, espectador? Um documentário deve ser objetivo? Mas o conceito de objetividade revela-se ainda mais frágil que o de realidade. Se entendermos por objetividade clareza na exposição das asserções,

centraremos nossa definição de documentário em uma questão estilística: de que modo expor com máxima clareza nossa interpretação sobre o fato que enunciamos? A resposta será múltipla, não incidindo sobre a definição do campo. Um documentário pode ser objetivo ou pouco claro e continuar a ser documentário (RAMOS, 2013, p. 30. Grifos do autor)
O excerto anterior parece problematizar a clássica definição de documentário fornecida pelo cineasta inglês John Grierson (1966), pois ele acreditava que tais produções operariam um tratamento criativo da realidade. A observação feita por Ramos nos permite alargar esse conceito e afirmar que o gênero é, na verdade, um recorte subjetivo de uma realidade. A subjetividade se dá pelo fato de que a enunciação fílmica, muitas vezes, é construída mediante a apreensão de um "real" percebido pelo documentarista. É importante notar que as motivações, crenças e valores, adquiridos interdiscursivamente por Adirley Queirós, implicam necessariamente, em seu projeto de fala.

O documentarista, nascido no interior de Goiás, se mudou para Brasília com três anos de idade, em meados de 1973. Naquele mesmo ano, Queirós, junto de seus familiares, rumou para Ceilândia motivados por uma campanha de assentamento. Diante desse quadro, percebemos que a história retratada em "A cidade é uma só?" possui pontos de contato com as experiências vivenciadas por seu diretor. Portanto, somos levados a considerar que o gênero documentário não somente pode ser analisado como um recorte subjetivo da realidade, como, também, um lugar de encenação do processo de rememoração. Veremos isso com mais precisão no decorrer do nosso artigo.

O segundo aspecto, conforme apontamos anteriormente, é o da ficcionalidade. Ao longo da história, percebemos a existência de diversas produções documentais que primam em imiscuir os gêneros 
cinematográficos. Se pensarmos em exemplos canônicos como "Terra sem pão" (1933), de Luis Buñuel e "Nanook, o Esquimó" (1922), de Robert Flaherty, passando por produções mais recentes, principalmente as brasileiras, como "Serras da desordem" (2006), de Andrea Tonacci e "O Olmo e a Gaivota" (2014), de Petra Costa, veremos que a produção documental, em diversos momentos, utiliza elementos como encenação, reencenação e representação terceiro elemento parece ser o mais caro à enunciação fílmica de "A cidade é uma só?". Existe uma vasta literatura teórica que dá conta desses fenômenos, de forma que, para amparar nossas ideias, utilizaremos o próprio Adirley Queirós, pois sua fala nos permite compreender a intencionalidade almejada pelo cineasta.

Segundo Queirós, "representar pode mostrar muito mais do que não representar, vamos assim dizer: pode ser muito mais forte, muito mais sincero. Talvez a representação seja muito mais sincera do que a nãorepresentação" (QUEIRÓS, 2013, p. 55). O fragmento anterior se mostra polêmico, pois, de alguma forma, o autor, legislando em causa própria, é veemente ao atrelar o valor de sinceridade a uma mise-enscène que se municia da ficcionalidade e da representação. $\bigcirc$ principal argumento defendido por ele é de que a "veracidade" é impossível de ser plenamente apreendida em função do elemento mediador da interação entre cineasta e ator social, qual seja, a câmera.

(...) a gente vê que essas relacões de representação são muito mais fortes dentro da história do cinema do que você ficar ali naquela coisa etnográfica... Elas são muito mais fortes do que você querer que o personagem seja ele mesmo - ser ele mesmo como, cara? Ninguém é ele mesmo frente à câmera! Ninguém pode ser ele mesmo nessa situação (QUEIRÓS, 2013, p. 58)

Nesse ínterim, é válido buscar um concatenamento das ideias no sentido de refletir como esse imbricamento genérico é utilizado de forma funcional, ou seja, não é um mero exercício estilístico, mas, sim, algo utilizado para conferir um efeito de significação. Cláudia Mesquita problematiza esse modus operandi adotando uma chave de resposta interessante. A autora percebe que, no chamado núcleo propriamente documental - que gira em torno da personagem Nancy -, parece haver um "maior controle, planejamento e estabilidade técnica e estética engendrando imagens e falas mais de acordo com nossa expectativa prévia de um documentário 'histórico', (MESQUITA, 2013, p. 75). Por outro lado, a pesquisadora percebe que no núcleo ficcional, há marcas mais significativas de indeterminação, trazendo um sentido de maior urgência para aquilo que é projetado na tomada. Façamos a conclusão desse tópico com as palavras de Adirley Queirós, que, em suma, parece não se preocupar com taxonomias genéricas:

(..) Eu acho que essa relação orgânica é muito mais forte do que a proposta de documentário e ficção, entendeu? Muito mais do que a tentativa de inverter o que é documentário e o que é ficção, o que é ficção Ou documentário, é o material estético do filme. Quando eu falo "material estético" eu penso na película, no som - porque a gente vai estabelecer o jogo ali. E ele vai se estabelecendo e vai se naturalizando

(QUEIRÓS, 2013, p. 59. Grifo do autor)

\section{A DISCURSIVIZAÇÃO DA MEMÓRIA}

No início de nosso texto trouxemos uma dicotomia proposta por Sírio Possenti (2015), na qual o linguista brasileiro estabelece uma contraposição entre história tradicional e história serial. Tal teorização nos remete ao trabalho do historiador francês Pierre Nora (1993), em que se percebe um antagonismo notório entre memória e história.

O ponto de contato entre Possenti (2015) e Nora (1993) se dá mediante a noção de que o segundo pensa a história como uma reconstrução, um recorte do passado que operaria um enrijecimento da memória, ademais a história, nessa concepção, se assemelharia à chamada história tradicional, que, comumente, coloca em segundo plano os grupos excluídos - pobres, negros, homossexuais, indígenas - e suas manifestações políticas e culturais. Por outro lado, a memória, para Nora (1993) é marcada pelo dinamismo, sendo factível raciocinar que ela contribui para o fortalecimento da chamada história serial. Nessa lógica, a diferença entre as duas visadas históricas se daria na maneira como a memória é instrumentalizada. 
A tradicional se municia da memória para, a posteriori, a esvaziar. "Tudo que é chamado hoje de memória não é, portanto, memória, mas já história. Tudo que é chamado clarão de memória é a finalização de seu desaparecimento no fogo da história" (NORA, 1993, p. 14). No excerto a seguir, o historiador francês estabelece uma ilustrativa contraposição que contribuirá nas ideias que estamos buscando desenvolver:

A memória é viva, sempre carregada por grupos vivos e, nesse sentido, ela está em permanente evolução, aberta à dialética da lembranca e do esquecimento,

inconsciente de suas deformações

sucessivas, vulnerável a todos os usos e manipulações,

suscetivel de longas latências e repentinas revitalizações.

história é a reconstrução sempre problemática e incompleta do que não existe mais. A memória é um fenômeno sempre atual, um elo vivido no eterno presente; a história, uma representação do passado (NORA, 1993, p. 9)

Em "A cidade é uma só?" temos a presença dos dois processos. Contudo, o caráter de resistência do trabalho de Adirley Queirós visa estabelecer uma desconstrução, pois o que se busca em seu material é a valorização da memória, ou seja, há um objetivo explícito de problematizar a "representação do passado", que é sempre construída por um grupo vinculado, segundo Althusser (1997), aos aparelhos ideológicos de estado. Evocando a classificação proposta por Possenti (2015), a história tradicional traz como característica 0 silenciamento ${ }^{4}$ dos assentados, ao passo que a história serial, de visada memorialística, almeja iluminar a trajetória daqueles que foram iludidos por um estado de coisas que buscava, tão somente, "higienizar" a moderna cidade de Brasília.

Todos os apontamentos anteriores nos fazem considerar - gênero documentário como um potencial instrumento de luta discursiva. Por esse ângulo,

os documentários memorialísticos trazem como uma possível característica a problematização

desconstrução de conceitos e de narrativas tidas como canônicas. À vista disso, faz-se necessário apresentar um pequeno panorama a respeito da noção de memória dentro dos estudos discursivos, uma vez que, inegavelmente, ela é uma noção interdiscursiva.

Podemos elencar Jean-Jacques Courtine como um dos primeiros nomes na condução de pesquisas ligadas à memória junto à Análise do Discurso. O autor francês, orientando de Michel Pêcheux, publica uma tese de doutorado cujo objetivo era analisar 0 discurso comunista em fricção com o discurso cristão. A ideia era compreender o cerne do antagonismo existente entre os dois grupos e como que os comunistas primaram no desenvolvimento de estratégias discursivas que visavam uma aproximação. O conceito mais importante formulado por Courtine é o de memória discursiva, que "diz respeito à existência histórica do enunciado no interior de práticas discursivas regradas por aparelhos ideológicos" (COURTINE, 2014, p. 105-106)

Uma das fontes inspiradoras para a problematização operada pelo autor francês foi o trabalho do sociólogo Maurice Halbwachs (2015), cuja contribuição para os estudos memorialísticos se dá na aplicação do conceito de memória coletiva. Para o teórico em questão, a noção de pertencimento se faz fulcral pois é a partir dela que podemos considerar a possibilidade de haver compartilhamento de valores, crenças e saberes. Analisando "A cidade é uma só?", perceberemos pontos de contato entre os atores sociais que compõe a obra, lembrando que todos os envolvidos possuem laços estritos com a cidade de Ceilândia.

(...) os fatos e ideias que mais facilmente recordamos são do terreno comum, pelo menos para um ou alguns ambientes. Essas lembranças existem 'para todo o mundo' nesta medida e é porque podemos nos apoiar na memória dos outros que somos capazes de recordá-la a qualquer momento e quando o desejamos.

(HALBWACHS, 2015, p. 66-67)

$O$ que se pode perceber, portanto, é que tanto a memória discursiva, q uanto a memória coletiva são noções ancoradas em compartilhamento, sendo o interdiscurso 0 propiciador dessa noção de pertencimento. 
Em Courtine (2014), o que está em jogo é a circulação dos enunciados, que surgem amparados por um continuum entre o passado e o presente. Já Halbwachs (2015) lida com a questão da memória individual que se mostra atrelada aos valores circulantes em uma determinada sociedade. Todas essas noções são impactadas pelo acionamento da história tradicional, no sentido de que esta, de alguma forma, proporciona as formulações narrativas. A memória coletiva, ao ser apreendida pela história, pode desconsiderar

manifestações de grupos excluídos, ao passo que a memória discursiva, sofrendo a mesma apreensão que a primeira, corre o risco de que determinadas noções e determinados conceitos e saberes sejam esvaziados de sentido. A história serial seria o caminho contrário, isto é, o mecanismo de resistência contra aquilo que Marie-Anne Paveau nomeia de amemória, que seria "um apagamento, consciente ou inconsciente, de um passado ou de um legado discursivo, de 'formulaçõesorigem' sobre as quais o falante não gostaria ter mais nada que dizer" (PAVEAU, 2015, p. 237. Grifos da autora).

O conceito de amemória, segundo Paveau (2015) se relaciona com a denegação do discurso sobre um determinado acontecimento. Esse fenômeno se faz mais presente em circunstâncias traumáticas, o que nos leva ao entendimento de que a remoção e a posterior transferência de milhares de moradores para locais inadequados se mostram terrenos férteis para a materialização do conceito formulado pela pesquisadora francesa. O discurso oficial, em vista disso, pode lançar mão da amemória para apagar certos rastros, construindo uma narrativa "higienizada", ou seja, essa denegação, ao contrário de uma ação individual, seria estimulada externamente por um estado de coisas afetado por uma classe que domina a narrativa.

Em paralelo com a amemória, Paveau desenvolve a ideia de desmemória discursiva, "um conjunto de fenômenos que possibilitam a revisão das linguagens discursivas, ou seja, das transmissões semânticas cultural

socialmenterealizadas pelos instrumentos da tecnologia discursiva" (PAVEAU, 2015, p 237. Grifo da autora). Em suma, a definição anterior é facilmente identificada com a concepção de revisionismo, voltada para uma desconstrução narrativa de fatos considerados indesejáveis por aqueles que estão narrando a história. Mostra-se, por exemplo, muito mais vantajoso, para a classe que domina a tecnologia discursiva, narrar a história de Brasilia deixando em segundo plano a atuação dos "candangos" e levando ao esquecimento o destino que muitos deles tiveram. O que se pode notar é que as cidades satélites e seus moradores, sendo Ceilândia a maior delas, parecem não interessar aos livros de história e aos discursos oficiais.

Em face do exposto, chegamos à ideia central de nosso artigo, que é a possibilidade de analisar o gênero documentário como um instrumento de resistência em favor do acionamento da história serial. Partimos do princípio de que "A cidade é uma só?" oferece um vasto arsenal de estratégias que buscariam reverter os processos de silenciamento, amemória e desmemória enfrentados pelos moradores de Ceilândia. É isso que tentaremos evidenciar no próximo tópico.

\section{O DOCUMENTÁRIO COMO INSTRUMENTO DE RESISTÊNCIA}

Primeiramente, é válido trazer para nossa discussão um conceito que se mostra caro à Análise do Discurso. Estamos falando das condições de produção do discurso, que também revelam um aspecto curioso no documentário em questão. Antes da projeção, recebemos - em forma

deletreiro - uma importante informação: "A cidade é uma só?" "foi parcialmente produzido com recursos do edital no 7, de 2010, com a temática "Brasília: 50 anos", do Ministério da Cultura e TV Brasil". Ora, por se tratar de uma seleção que prima em homenagear a cidade, era de se esperar uma produção mais, digamos, atravessada pelo discurso epidítico. O que temos é justamente o contrário, uma vez que Adirley Queirós constrói uma obra que, de alguma forma, cria uma espécie de contradiscurso. Nesse sentido, se faz notória a utilização de uma organização antitética em relação ao chamado discurso oficial.

primeiro discurso funcionaria como uma espécie de ode à Brasília e a ideia seria enaltecer as qualidades da jovem cidade. O contradiscurso é a desconstrução desse pensamento por meio de uma artimanha narrativa que evidencia o caráter desigual em que a capital brasileira foi projetada. Vale dizer que, para ser aprovado no edital, Adirley Queirós elabora um projeto destoante em relação ao verdadeiro objetivo. Podemos pensar que, se o projeto fosse 
submetido evidenciando a real intencionalidade do cineasta, dificilmente ele seria aprovado. Voltando à noção de contradiscurso, é válido destacar uma das primeiras falas de Nancy, pois ela explica como funcionava a Campanha de Erradicação das Invasões. O proferimento se situa em relação direta com o chamado discurso oficial. Adirley posicionou no fio do discurso as duas falas em relação contígua, buscando, assim, evidenciar o antagonismo. Vejamos, primeiramente, o discurso da classe dominante, presente no documentário por meio de imagens de arquivo:

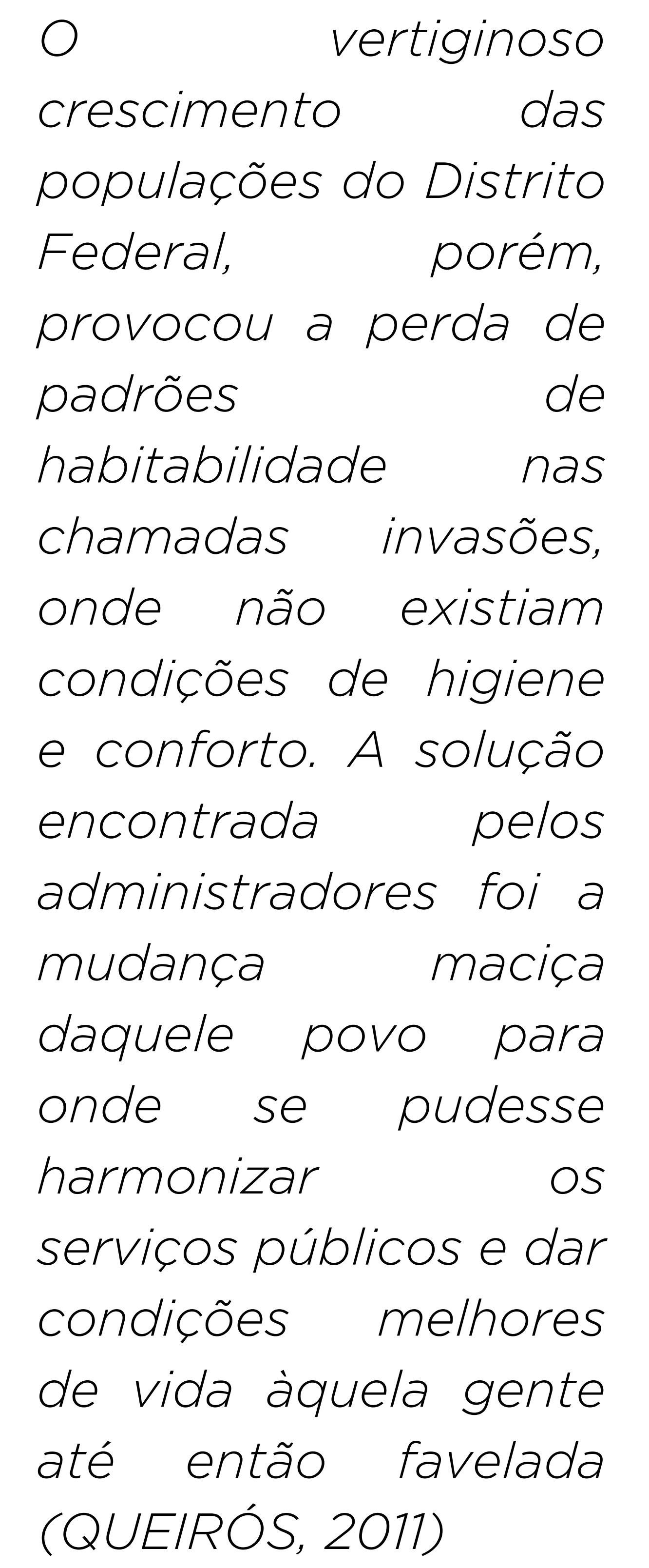

A fala de Nancy, como veremos, é frontalmente oposta ao discurso vendido pela classe política dominante:

O discurso deles era que iam tirar de lá pra uma situação legalizada, com lote, com toda a infraestrutura, e na verdade não foi isso, né? Quando a gente chegou aqui, não tinha nada disso também. 0 que eles queriam na verdade era achar um lugar pra jogar aquele monte de pobre né? Tirar a coisa feia que era lá, próxima de Brasilia e trazer pra um lugar mais distante possivel. E, quando nós chegamos aqui, foi um outro choque, porque era muito mato, muita terra, poeira e "infra" nenhuma (QUEIRÓS, 2011)

Apresenta-se pertinente recuar nas cenas iniciais de "A cidade é uma só?", em que salta aos olhos a primeira utilização da antítese, uma marca latente na enunciação fílmica do cineasta. Logo após a informação reveladora das condições de produção do documentário, Adirley Queirós utiliza os arquivos por intermédio de uma sonora que traz a voz de Oscar Niemeyer: "Aí está Brasília, tantos anos passados... A cidade que JK construiu com tanto entusiasmo. Uma cidade que viveu como uma grande metrópole" (QUEIRÓS, 2011). Em seguida, aparece o letreiro identificador da produção, localizado em meio a uma gigantesca e simbólica letra "X". A oposição é explícita, pois enquanto a voz do arquiteto é inserida na projeção, vemos imagens, através de uma câmera subjetiva, situada no interior de um automóvel possivelmente de Zé Bigode que evidenciam a precariedade das condições de vida dos moradores da Ceilândia. Eis um recurso significativo utilizado pelo cineasta, pois o fato de Zé Bigode ser um corretor imobiliário em busca de terras para negociar pode ser interpretado como um pretexto, uma vez que, a partir desse personagem, conseguimos compreender a vastidão territorial da cidade e como ela foi mal organizada.

Além da antítese, notamos, também, a ressignificação presente, por exemplo, na problematização da mencionada letra "X". Nancy nos explica a sua função junto à Campanha de Erradicação das Invasões: Olha só... Tava você lá no seu barraco, tranquilamente... Ai, de repente, chegava uma equipe fazia um " $X$ " no seu barraco. E não tinha muita explicação, né? Você não entendia muito bem o porquê daquele " $X$ ". E esse " $x$ " era pra indicar que o barraco já estava, de fato, legalizado dentro da vila do IAPI pra ser transferido pra Ceilândia. Então, quem tinha um " $X$ " no barraco é porque tinha sido "sorteado" pra ir pra Ceilândia. [...] Não tinha opção. Eles queriam limpar o lugar (QUEIRÓS, 2011)

Interessante analisar o caráter semântico por trás da letra "X", uma vez que ele significava a interdição e posterior expulsão, camufladas por um discurso atenuador, já que os moradores das casas eram, conforme proferimento de Nancy, "sorteados". A ideia é transmitir uma sensação de honraria, pois tais pessoas, ao contribuírem para a "melhoria" das condições de vida de Brasília, eram contempladas com um lote "bem estruturado" e "bem localizado". Momentos antes de Nancy revelar o real significado da letra, vemos o candidato do fictício Partido da Correria Nacional (PCN), Dildu, fazendo 
uma campanha de rua, acompanhado de sua equipe de "marqueteiros". O detalhe é que em sua camisa há uma enorme letra "X", com o nome Dildu escrito logo abaixo. Parece-nos que a ideia é ressignificar o caráter semântico desse símbolo, no sentido de que no processo de erradicação, O " $X$ " era imposto, significando a expulsão velada, ao passo que na campanha de Dildu, tal letra significa o livre arbítrio para escolher um candidato alinhado com os interesses de uma classe marginalizada. Ninguém melhordo que o próprio Dildu para explicar a simbologia:

A ideia do "X" é a ideia que a gente ressignificou tudo que já rolou de ruim no passado. A gente pega a nossa história e vê como é isso pra nós, o que significou o "X". Por exemplo, meu pai ficou grilado com a coisa do barraco e saiu pra ver que barulho era aquele: "que diabo de " $X$ " é esse?" (QUEIRÓS, 2011)

A campanha de Dildu, vale destacar, é muito curiosa, pois ela se caracteriza pela alta precariedade. Veículo em péssimas condições, que estraga no meio da rua; carro de som simples, tocando em alto e bom som um jingle eficiente, mas gravado em condições destoantes em relação ao trabalho dos marqueteiros dos grandes partidos políticos brasileiros; uma equipe empenhada em ajudar o candidato, porém marcada por um acentuado grau de amadorismo, se compararmos com a estrutura dos partidos políticos. $\bigcirc$ que se vê, mediante os elementos destacados, é a utilização da estratégia do humor na tentativa de captar a atenção do público para uma realidade silenciada pelo discurso oficial e que ainda apresenta marcas dos traumas vivenciados em um passado não tão distante.

No que diz respeito à questão memorialística, Adirley Queirós, conforme apontamos ao longo do texto, parece querer combater a amemória e a desmemória discursiva através da subversão e do esfacelamento da fronteira existente entre os gêneros cinematográficos. $\bigcirc$ primeiro artifício se constrói por meio da inscrição do passado no presente, no sentido de que aquilo que fora vivenciado possa ser atualizado, conferindo um sentido de atemporalidade para as ações opressoras do passado. Aqui, percebemos a atenção do processo de enunciação fílmica para a categoria tempo.

O documentarista afirma que a Ceilândia é um "aborto" de Brasília, ao mesmo tempo em que a capital federal, para ele, "era a negação [que só podia ser vista] pelo negativo" (QUEIRÓS, 2013, p. 41). O que isso significa? $\bigcirc$ fato é que a negativação denota uma espécie de impossibilidade. Em diversos momentos, vários personagens de "A cidade é uma só?" deixam transparecer que Brasília é uma espécie de muro de difícil transposição. É notório que a questão da memória encontra ressonância principalmente, na utilização dos chamados arquivos, mas, até nisso, Adirley Queirós produz uma subversão. Quem analisa essa estratégia é a pesquisadora Cláudia Mesquita:

$$
\begin{aligned}
& \text { (...) A cidade é uma } \\
& \text { só? duas vezes } \\
& \text { subverte: produzindo }
\end{aligned}
$$

arquivos (subversão cinematográfica), e fazendo-o da perspectiva dos vencidos (que se permitem, equipe e Nancy em parceria "imitando" os poderes, manipular a memória, recriando vestígios da propaganda oficial). Essa tomada da imagem ganha forca se pensarmos que, neste filme, o ponto de vista

dosvencedores só comparece indiretamente, através - justamente - dos arquivos: campanhas de propaganda, representações idealizantes de Brasilia, manchete de jornais, etc. No mais, tudo se resume às andanças, ações e rememorações de três moradores de Ceilândia (MESQUITA, 2013, p. 82 e 83)

É nesse ponto que achamos válido inserir a complementaridade da memória e da vivência do cotidiano. Os três personagens simbolizam efeitos de sentido proporcionados pela relação temporal. Nancy, por exemplo, é aquela que "revira" os arquivos, sendo a personagem que confere à produção uma aura de

documentário, pensado em moldes canônicos. Apesar disso, ela realiza uma desconstrução, pois há um processo de recriação, que, segundo Cláudia Mesquita (2013), prima em trazer à tona a memória dos vencidos. Levando em consideração o supracitado edital, a expectativa seria de que os arquivos funcionassem como elementos elogiosos à construção da cidade de Brasília. Os chamados arquivos 
oficiais se fazem presentes, mas são constantemente desconstruídos.

O processo de recriação dos arquivos se dá pela tentativa de rememorar a gravação do jingle pertencente à Campanha de Erradicação das Invasões. Nancy tem a missão de escolher crianças para gravar, novamente, a peça propagandista. Adirley Queirós, subvertendo a normalidade, insere essa rememoração mediante uma fotografia em preto e branco para dar a entender que ela era um arquivo oficial encontrado pela equipe. Há um efeito simbólico nesse expediente, pois ele suscita a ideia de que o jingle é atemporal, uma vez que Ceilândia segue sendo tratada como, nas palavras de Adirley Queirós(2013), um “aborto”.

Zé Bigode e Dildu são detentores da função de atualização. Nancy relembra as consequências da remoção e como ela foi traumatizante para os moradores da "invasão". Ela é a marca do passado, sendo a personagem que lança mão dos arquivos - jornais antigos que convocavam as crianças para a gravação do jingle, além

de manusear diversas fotografias daquela época.

Os dois personagens supramencionados, ao contrário, funcionam como uma inscrição do presente. Eles exemplificam para 0 espectador as dificuldades enfrentadas pelos moradores da Ceilândia. Zé Bigode exerce a tarefa de guiar o nosso olhar pela longa extensão territorial daquela região. Dildu também o faz, e nessa perspectiva é interessante destacar as cenas em que eles perambulam pelo chamado Plano Piloto, pois é transmitida uma sensação de inadequação,

passagens. Em diálogos simples, e aparentemente banais, os dois revelam a acentuada disparidade socia existente entre o plano piloto e as cidades satélites: em uma determinada cena, Dildu, se referindo aos inúmeros prédios cujos apartamentos apresentam ar condicionado afirma: "Nós tossindo seco e eles tossindo molhado".

O que se percebe em "A cidade é uma só?", além de um desdobramento temporal, é uma contra argumentação discursiva. Nancy, por exemplo, lê uma notícia antiga datada do dia 01/04/1971 que afirmava: "falta apenas um mês para a Ceilândia ficar pronta para receber os moradores". O diretor afirma após a leitura: "dia da mentira, né"? Nancy responde sorrindo: "pois é". Outro contradiscurso fundamental é o jingle utilizado pela fictícia campanha eleitoral de Dildu. A canção da CE atestava a ajuda dos governantes para a construção de um lar "decente" aos moradores. A promessa de campanha de Dildu mostra que, na verdade, não houve auxílio nenhum, o que houve, ao contrário, foi esquecimento. Vejamos o que Dildu promete:

Vamos obrigar aqui as escolas públicas também da satélite ofereçam o curso de formação para serviço público! Chega de hereditariedade para servidor de estado! Nós vamos botar a favela para aprender! E virar classe média cabulosa também! Chega desse negócio de um só comer o pão e os outros ficarem vendo só o que a rodoviária tem. Nós vamos também fazer cinema de $R \$$ 1,00! Filme de amor, filme de bandido, filme de aventura e caratê! Nós vamos ter também $R \Phi$ 1,00: é a nossa comida na rodoviária e o nosso cardápio tem que ser digno. Vamos obrigar os hospitais a receber o pessoal do externo sem precisar apresentar fato e enderecco. A saúde tem que ser de qualidade já! (QUEIRÓS, 2011)

É possivel sintetizar as promessas contidas na campanha de Dildu através de uma única asserção: É preciso eliminar a disparidade existente entre o plano piloto e as cidades satélites. Ora, há um ponto, no excerto anterior, que chama a atenção. Quando, na última reivindicação, ele nomeia os habitantes da cidade satélite como "pessoal do externo", há a pressuposição de que existe o "pessoal interno", ou seja, há um "pessoal" privilegiado, cuja condição de vida é, acentuadamente, oposta àquela vivenciada, por exemplo, pelos moradores da Ceilândia. Esse "pessoal do interno" tem seu espaço garantido na história tradicional, ao passo que o "pessoal do externo" tem que lançar mão de estratégias de resistência para romper com 0 processo de silenciamento.

\section{CONSIDERAÇÕES}

FINAIS

O principal questionamento a ser feito, após todos os apontamentos construídos ao longo do texto, gira da relevância de "A cidade é uma só?" dentro da filmografia documental brasileira. $\bigcirc$ filme 
tendo sido produzido em 2011 nos faz pensar acerca da necessidade de abordá-lo quase uma década após sua realização. Em primeiro lugar, julgamos válido o processo de resistência contra o apagamento memorialístico. O trabalho de Adirley Queirós primou em lançar luzes para uma realidade brasileira que ainda se apresenta desconhecida do grande público. Em segundo lugar, constatamos que a enunciação fílmica do filme em questão e é marcada pela desconstrução e pela subversão de expectativas. Dessa maneira, concluímos que - trabalho de Queirós é marcado por uma dinâmica de imbricamento entre os gêneros fílmicos, lembrando que, mesmo em momentos de predomínio da ficção ou da mise-en-scène documental, ocorre um procedimento subversivo.

Alguns conceitos trabalhados ao longo do artigo, a nosso ver, encontram impacto em "A cidade é uma só?", cujo fio condutor de todas as discussões é o deslizamento entre história tradicional atravessada pelo discurso oficial - e a história serial - apagada por esse discurso. Assim sendo, constatamos que os documentários voltados para a resistência contra os silenciamentos - aqueles que primam em esmiuçar acontecimentos da ordem da história serial - são comumente relevantes e podem originar instigantes materiais para análise.
REFERENNCIAS

A CIDADE é uma só? Direção: Adirley Queirós. Produção:

Adirley Queirós e André Carvalheira. Intérpretes: Nancy Araújo, Dilmar Durães (Dildu),

Wellington Abreu e outros.

Roteiro: Adirley Queirós. Música original: Guile Martins. Ceilândia. Ceicine, Cinco da Norte CEl, 400 Filmes, 2011. 1 DVD (79 min.), widescreen, cor. Produzido por Ceicine, Cinco da Norte CEl, 400 Filmes.

ALTHUSSER, Louis. Aparelhos Ideológicos do Estado. 3a edição. Rio de Janeiro: Edições Graal, 1987.social. São Paulo: Contexto, p. 49-60, 2015.

NICHOLS, Bill. Introdução ao documentário. 5a Ed. Campinas, SP: Papirus, 2014

COURTINE, Jean-Jacques. Análise do discurso político: o discurso comunista enderecado aos cristãos. 1a ed., 1a

reimpressão. São Carlos:

Edufscar, 2014

FOUCAULT, Michel. "Retornar à história". In: Ditos e escritos II. Rio de Janeiro: Forense Universitária, 1972, p. 282-285.

GRIERSON, John. "First Principles of documentary" in HARDY Forsyth (ed.) Grierson on documentary, Revised Edition, Berkeley and Los Angeles: University of California Press, 1966.

GUIDI, Milza. Incansáveis moradores da Ceilândia: uma história de lutas. Brasília, DF. Edição do autor, 2013.
MENA, M. C.; IMANISHI, R.; REIS, C. "Entrevista com Adirley Queirós". In: Revista Negativo. Cineclube Beijoca. Brasilia, Universidade de Brasilia Departamento de Filosofia: v. T, n.7, p. 17-70, 2013.

MESQUITA, C. "Um drama documentário? Atualidade e história em 'A cidade é uma só?'”. In: Revista Negativo: Cineclube Beijoca. Brasília, Universidade de Brasília -

Departamento de Filosofia: v. 1, n. 1, p. 71-86, 2013.

NORA, Pierre. "Entre memória e história: a problemática dos Iugares". In: Projeto História. Revista do Programa de Estudos Pós Graduados de História. São Paulo, PUC SP, Departamento de História: v. 10, p. 7-28, 1993.

ORLANDI, Eni Pulccinelli. As formas do silêncio: no movimento dos sentidos. $4^{a}$ ed Campinas, SP: Editora da Unicamp, 1997

PAVEAU, Marie-Anne. Linguagem e moral: uma ética das virtudes discursivas. Campinas, SP: Editora da Unicamp, 2015

\section{POSSENTI, S. "Durações} históricas e sua relação com o público e privado". In: LARA, Gláucia Proença, LIMBERTI, Rita Pacheco (Orgs.). Discurso e desigualdade social. São Paulo: Contexto, p. 49-60, 2015.

RAMOS, Fernão Pessoa. Mas afinal... O que é mesmo documentário? 2a ed. São Paulo: Editora Senac, 2013.
HALBWACHS, Maurice. A memória coletiva. $2^{a}$ ed., $8^{a}$ reimpressão. São Paulo:

Centauro, 2015 
- "A cidade de Ceilândia foi originalmente formada por construtores de Brasília, exmoradores das antigas Vilas IAPI, Tenório e adjacências, no entorno do plano piloto. (...) $\dot{A}$ CEl, órgão constituido em sua maioria por senhoras da alta sociedade, coube a tarefa de convencer os moradores das chamadas invasões de que a transferência lhes ofereceria muitas vantagens, tais como posse do lote, água encanada, asfalto, escola, hospitais, creches, etc. A remoção ocorreu no período de 27 de março de 1971 a 08 de março de 1972" (GUIDI, 2013, p. 11).

2 - "Vamos sair da invasão? A cidade é uma só! Você que tem um bom lugar pra morar, me dê a mão, ajude a construir nosso lar para que possamos dizer juntos a cidade é uma só. Você, você, você. Você vai participar. Por que? Por que? Por que? A cidade é uma só" (QUEIRÓS, 2011).

3 - Produtor e cineasta inglês, que contribuiu na organização de vários grupos de produção, dentre os quais o GPO Unit (1933-1937). Muitos o consideram o inventor do documentário moderno, estando, igualmente, na origem do Office National du Film do Canadá (ONF), um dos mais importantes centros produtores dos chamados documentários do cinema direto (movimento iniciado no final dos anos 1950 que foi impulsionado pelos avanços tecnológicos que permitiam a captura do som no momento da enunciação filmica, no sentido de possibilitar uma sincronia entre o som e a filmagem).

4 - Ao utilizarmos tal noção, estamos no filiando à teorização proposta por Orlandi (1997) que pensa o silenciamento como um efeito discursivo de sentido. A autora nota que "como o sentido é sempre produzido de um lugar, a partir de uma posição do sujeito - ao dizer, ele estará, necessariamente, não dizendo "outros" sentidos. Isso produz um recorte necessário no sentido. Dizer e silenciar andam juntos. (ORLANDI, 1997, p. 55).

Recebido em 26 mar 2019 | Aprovado em 03 dez 2019

Fábio Ávila Arcanjo

Doutorando do Programa de Pós-Graduação em Estudos Linguísticos da Universidade Federal de Minas Gerais (UFMG).

E-mail: fabioarcanjo1981@hotmail.com 